\title{
Low Levels of CD36 in Peripheral Blood Monocytes in Subclinical Atherosclerosis in Rheumatoid Arthritis: A Cross-Sectional Study in a Mexican Population
}

\author{
Eduardo Gómez-Bañuelos, ${ }^{1}$ Beatriz Teresita Martín-Márquez, ${ }^{1}$ \\ Erika Aurora Martínez-García, ${ }^{1,2}$ Mauricio Figueroa-Sanchez, ${ }^{3}$ Lourdes Nuñez-Atahualpa, ${ }^{3}$ \\ Alberto Daniel Rocha-Muñoz, ${ }^{1}$ Pedro Ernesto Sánchez-Hernández, ${ }^{4}$ \\ Rosa Elena Navarro-Hernandez, ${ }^{1}$ Perla Monserrat Madrigal-Ruiz, ${ }^{1}$ \\ Adan Alberto Saldaña-Millan, ${ }^{1}$ Sergio Duran-Barragan, ${ }^{1}$ Laura Gonzalez-Lopez, ${ }^{5}$ \\ Jorge Ivan Gamez-Nava, ${ }^{6}$ and Mónica Vázquez-Del Mercado ${ }^{1,7}$ \\ ${ }^{1}$ Instituto de Investigación en Reumatología y del Sistema Musculo Esquelético, Centro Universitario de Ciencias de la Salud, \\ Benemérita Universidad de Guadalajara, Sierra Mojada No. 950, Colonia Independencia, 44340 Guadalajara, JAL, Mexico \\ ${ }^{2}$ Departamento de Fisiología, Centro Universitario de Ciencias de la Salud, Benemérita Universidad de Guadalajara, \\ Sierra Mojada No. 950, Colonia Independencia, 44340 Guadalajara, JAL, Mexico \\ ${ }^{3}$ Servivio de Radiología e Imagen, Hospital Civil de Guadalajara "Fray Antonio Alcalde", Benemérita Universidad de Guadalajara, \\ Hospital No. 278, 44280 Guadalajara, JAL, Mexico \\ ${ }^{4}$ Laboratorio de Inmunología, Departamento de Fisiología, Centro Universitario de Ciencias de la Salud, \\ Benemérita Universidad de Guadalajara, Sierra Mojada No. 950, Colonia Independencia, 44340 Guadalajara, JAL, Mexico \\ ${ }^{5}$ Departamento de Medicina Interna-Reumatología, Hospital General Regional No. 110, Instituto Mexicano del Seguro Social, \\ Circunvalación Oblatos No. 2212, Colonia Oblatos, 44700 Guadalajara, JAL, Mexico \\ ${ }^{6}$ Unidad Médica de Alta Especialidad, Centro Médico Nacional de Occidente, Instituto Mexicano del Seguro Social, \\ Belisario Domínguez No. 1000, Independencia Oriente, 44340 Guadalajara, JAL, Mexico \\ ${ }^{7}$ Servicio de Reumatología, Hospital Civil "Dr. Juan I. Menchaca”, Benemérita Universidad de Guadalajara, Salvador de Quevedo \\ No. 750, 44100 Guadalajara, JAL, Mexico
}

Correspondence should be addressed to Mónica Vázquez-Del Mercado; dravme@hotmail.com

Received 20 March 2014; Revised 13 May 2014; Accepted 13 May 2014; Published 9 June 2014

Academic Editor: Miguel A. González-Gay

Copyright (C) 2014 Eduardo Gómez-Bañuelos et al. This is an open access article distributed under the Creative Commons Attribution License, which permits unrestricted use, distribution, and reproduction in any medium, provided the original work is properly cited.

\footnotetext{
Patients with rheumatoid arthritis (RA) have a higher risk for atherosclerosis. There is no clinical information about scavenger receptor CD36 and the development of subclinical atherosclerosis in patients with RA. The aim of this study was to evaluate the association between membrane expression of CD36 in peripheral blood mononuclear cells (PBMC) and carotid intima-media thickness (cIMT) in patients with RA. Methods. We included 67 patients with RA from the Rheumatology Department of Hospital Civil "Dr. Juan I. Menchaca," Guadalajara, Jalisco, Mexico. We evaluated the cIMT, considering subclinical atherosclerosis when $>0.6 \mathrm{~mm}$. Since our main objective was to associate the membrane expression of CD36 with subclinical atherosclerosis, other molecules related with cardiovascular risk such as ox-LDL, IL-6, and TNF $\alpha$ were tested. Results. We found low CD36 membrane expression in PBMC from RA patients with subclinical atherosclerosis $(P<0.001)$. CD36 mean fluorescence intensity had negative correlations with cIMT $(r=-0.578, P<0.001)$, ox-LDL $(r=-0.427, P=0.05)$, TNF $\alpha(r=-0.729, P<0.001)$, and IL-6 ( $r=-0.822$, $P<0.001)$. Conclusion. RA patients with subclinical atherosclerosis showed low membrane expression of CD36 in PBMC and increased serum proinflammatory cytokines. Further studies are needed to clarify the regulation of CD36 in RA.
} 


\section{Introduction}

Rheumatoid arthritis (RA) is a chronic autoimmune disease with systemic complications and early cardiovascular death [1]. RA patients are prone to develop atherosclerosis at a relatively young age.

Atherosclerosis and inflammation in RA share several mechanisms in their pathogenesis including proinflammatory cytokine expression, infectious agents, dyslipidemia, and autoantibodies [2-8].

Type B scavenger receptors (SR), like CD36, are molecules possibly involved in the pathogenesis of atherosclerosis. During atherogenesis, blood monocytes are recruited into the intima and subintima layers of blood vessels; were they internalize oxidized low density lipoproteins (ox-LDL) through SR (CD36). This process results in the activation of monocytes and their differentiation into macrophages and foam cells. As a consequence, matrix metalloproteinases, proinflammatory cytokines, and chemoattractants enhance inflammatory infiltrates and vascular remodeling $[9,10]$. CD36 has a critical role in the atherosclerotic plaque development [11-14]. However, their role in cardiovascular complications of RA has not been studied.

The aim of this study was to evaluate the association between membrane expressions of CD36 in peripheral blood mononuclear cells (PBMC) with carotid intima-media thickness (cIMT) in patients with RA without known traditional cardiovascular risk factors.

\section{Methods}

2.1. Patients. We recruited RA patients that met ACR 1987 criteria [15], from the Hospital Civil "Dr. Juan I. Menchaca" at Guadalajara, Jalisco, Mexico. Patients with known cardiovascular risk factors such as history of myocardiopathy, hypertension, diabetes mellitus, hyperlipidemia, malignancy, thyroid, renal or hepatic disease, smokers and steroid treatment $>10 \mathrm{mg} /$ day were excluded.

A structured questionnaire was applied to each patient to evaluate demographical and clinical variables. Physical examination, joint assessment, and venous blood drawn were performed at the visit.

2.2. Clinical Assessment. Disease activity was evaluated using Disease Activity Score 28 (DAS28) and C-reactive protein (CRP).

2.3. cIMT. It was assessed according to the recommendations defined by the Mannheim carotid intima-media thickness and plaque consensus (2004-2006-2011) [16] by a single operator using a high-resolution B-mode ultrasound (Philips Saronno, Italy) with a $9 \mathrm{MHz}$ transducer. Two segments from the common carotid artery (CCA), one from the carotid bifurcation $(\mathrm{BF})$, and two from the internal carotid artery (ICA) were evaluated. Mean cIMT values were calculated for each segment. Patients were classified according to the cIMT with a cut-off point of $0.6 \mathrm{~mm}$.
2.4. Laboratory Assessment. Serum was obtained by centrifugation of whole blood at 2,000 rpm for 15 minutes; aliquots with serum were stored at $-70^{\circ} \mathrm{C}$ for no longer than 6 months. Erythrocyte sedimentation rate (ESR) was measured using Wintrobe method and CRP by immunoturbidimetry (assay range $0.3-161 \mathrm{mg} / \mathrm{L}$, Randox laboratories limited); total cholesterol (TC), triglycerides (Tg), high density lipoprotein cholesterol (HDL-c), and low density lipoprotein cholesterol (LDL-c) were measured by routine methods. Cardiovascular risk ratio was calculated using the atherogenic index of plasma (AIP) which was defined as TC/HDL-c. Anticyclic citrullinated peptide (CCP) antibodies (intra-assay variation coefficient $(\mathrm{VC})<9 \%$ and interassay $\mathrm{VC}<11 \%$, Axis-Shield Diagnostics Ltd.), serum interleukin (IL)-6 (intra-assay VC $5.1 \%-7.7 \%$ and interassay VC 6.5\%-9.3\%, Invitrogen), tumor necrosis factor (TNF) $\alpha$ (intra-assay VC $4.2 \%-5.2 \%$ and interassay VC 4.6\%-7.4\%, R\&D Systems), and ox-LDL (intraassay VC 3.9\%-5.7\% and interassay VC 9.0\%-11.0\%, ALPCO Diagnostics) were measured by enzyme-linked immunosorbent assay (ELISA).

The flow cytometric analysis was performed using fluorescein isothiocyanate- (FITC-) conjugated mouse monoclonal antibodies against human CD36 and PE conjugated anti-human CD14 (BioLegend). PBMC were obtained by density gradient centrifugation using a lymphocyte separation solution. The cells were washed twice with phosphate buffered saline (PBS) and fixed with $1 \%$ paraformaldehyde for 20 minutes at $4^{\circ} \mathrm{C}$. After being washed with PBS, $5 \times 10^{6}$ cells in $50 \mu \mathrm{L}$ PBS were incubated with FITC or PE-conjugated monoclonal antibodies for 30 minutes at $4^{\circ} \mathrm{C}$. The cells were then washed twice before being assayed with a flow cytometer (Beckman Coulter, Epic XL, Miami, FL, USA) and analyzed with the software WinMDI 2.9.

2.5. Statistical Analyses. Values are presented as mean \pm standard deviation (SD) and percentages as appropriate. Between-group differences were estimated by independentsample Student's $t$-test. Chi-square test (or Fisher's exact test) was used to compare categorical variables. Spearman's correlation coefficient was calculated for cIMT, DAS28, CRP, anti-CCP, IL-6, and TNF $\alpha$. All data were analyzed using SPSS 18.0 software (SPSS Inc., Chicago, IL) and replicated using the software Stata 12.0 (StataCorp LP, Texas, USA), considering a two-tailed level of $P<0.05$ statistically significant.

2.6. Ethics. Protocol was approved by the IRB committee (register number 1068/10) of the Hospital Civil "Dr. Juan I. Menchaca” of the Benemérita Universidad de Guadalajara.

\section{Results}

Sixty-seven patients were included in this study; 60 (89.5\%) were female, with a mean (SD) age of 44.2 (11.9) years old; 29 (43.28\%) had evidence of increased cIMT. Table 1 shows the comparison of RA subgroups with and without increased cIMT. No statistical differences in age, disease duration, and disease activity were observed between higher and lower cIMT groups. The increased cIMT group $(>0.6 \mathrm{~mm})$ showed 
TABLE 1: Characteristics and comparison of RA subgroups with and without increased cIMT.

\begin{tabular}{|c|c|c|c|}
\hline \multirow{2}{*}{ Variable } & \multicolumn{2}{|c|}{ Study groups } & \multirow{2}{*}{$P$} \\
\hline & $\begin{aligned} \mathrm{cIMT} & \leq 0.6 \mathrm{~mm} \\
n & =38\end{aligned}$ & $\begin{aligned} \text { cIMT } & >0.6 \mathrm{~mm} \\
n & =29\end{aligned}$ & \\
\hline Age, years & $42.58 \pm 11.43$ & $47.74 \pm 12.54$ & 0.14 \\
\hline \multicolumn{4}{|l|}{$R A$ characteristics } \\
\hline Disease duration, years & $4.52 \pm 4.46$ & $3.40 \pm 5.50$ & 0.47 \\
\hline DAS28, units & $2.73 \pm 0.98$ & $3.48 \pm 1.12$ & 0.03 \\
\hline \multicolumn{4}{|l|}{ Lipid profile } \\
\hline $\mathrm{TC}, \mathrm{mg} / \mathrm{dL}$ & $176.39 \pm 34.83$ & $239.78 \pm 44.31$ & $<0.001$ \\
\hline $\mathrm{Tg}, \mathrm{mg} / \mathrm{dL}$ & $136.87 \pm 58.22$ & $195.33 \pm 63.95$ & 0.002 \\
\hline HDL-c, mg/dL & $51.87 \pm 15.34$ & $36.74 \pm 8.40$ & $<0.001$ \\
\hline LDL-c, mg/dL & $109.00 \pm 24.50$ & $111.45 \pm 27.74$ & 0.75 \\
\hline VLDL-c, mg/dL & $27.79 \pm 10.91$ & $32.85 \pm 16.10$ & 0.17 \\
\hline ox-LDL, mg/dL & $55.62 \pm 5.38$ & $219.48 \pm 98.58$ & $<0.001$ \\
\hline AIP, TC/HDL-c & $3.66 \pm 1.26$ & $6.77 \pm 1.72$ & $<0.001$ \\
\hline \multicolumn{4}{|l|}{ Serological profile } \\
\hline $\mathrm{ESR}, \mathrm{mm} / \mathrm{h}$ & $24.03 \pm 19.67$ & $21.14 \pm 9.03$ & 0.52 \\
\hline RF, IU/mL & $97.18 \pm 101.12$ & $134.18 \pm 133.94$ & 0.61 \\
\hline CRP, mg/L & $3.83 \pm 2.61$ & $13.29 \pm 6.31$ & $<0.001$ \\
\hline $\mathrm{TNF} \alpha, \mathrm{pg} / \mathrm{mL}$ & $64.72 \pm 9.28$ & $104.75 \pm 17.49$ & $<0.001$ \\
\hline IL-6, pg/mL & $29.03 \pm 3.43$ & $99.45 \pm 11.29$ & $<0.001$ \\
\hline Anti-CCP, U/mL & $73.22 \pm 65.92$ & $154.62 \pm 97.70$ & 0.004 \\
\hline \multicolumn{4}{|l|}{ Flow cytometry } \\
\hline CD36, MFI & $170.43 \pm 38.80$ & $67.09 \pm 27.50$ & $<0.001$ \\
\hline \multicolumn{4}{|l|}{$D M A R D s$} \\
\hline Methotrexate, $n(\%)$ & $36(94.7)$ & $29(100)$ & 0.14 \\
\hline Time of use, years & $4.51 \pm 4.42$ & $3.30 \pm 5.27$ & 0.06 \\
\hline Chloroquine, $n(\%)$ & $21(55.3)$ & $15(51.7)$ & 1.00 \\
\hline Sulfasalazine, $n(\%)$ & $9(23.7)$ & $4(13.8)$ & 0.52 \\
\hline Azathioprine, $n(\%)$ & $6(15.8)$ & $4(13.8)$ & 1.00 \\
\hline Corticosteroids, $n(\%)$ & $3(7.9)$ & $1(3.5)$ & 0.45 \\
\hline
\end{tabular}

RA: rheumatoid arthritis; cIMT: carotid intima-media thickness; DAS28: disease activity score; TC: total cholesterol; Tg: triglycerides; HDL-c: high density lipoprotein cholesterol; LDL-c: low density lipoprotein cholesterol; VLDL-c: very low density lipoprotein cholesterol; AIP: atherogenic index of plasma; ESR: erythrocyte sedimentation rate; RF: rheumatoid factor; CRP: C-reactive protein; TNF $\alpha$ : tumor necrosis factor alpha; IL: interleukin; anti-CCP: anticyclic citrullinated peptides; MFI: mean fluorescence intensity; DMARDs: disease-modifying antirheumatic drugs.

Qualitative variables are expressed as frequencies (\%); quantitative variables are expressed as means \pm standard deviations (SD). Comparisons between proportions were computed using Chi-square or Fisher exact test. Comparisons between medians were computed with unpaired Student's $t$-test.

higher serum levels of TC $(P<0.001)$, Tg $(P=0.002)$, oxLDL $(P<0.001)$, and AIP $(P<0.001)$ and lower serum levels of HDL-c $(P<0.001)$ compared with the cIMT group $(<0.6 \mathrm{~mm})$. Serum levels of CRP, TNF $\alpha$, IL-6, and anti-CCP also were higher in the increased cIMT group $(P<0.001)$.

3.1. CD36 PBMC Membrane Expression. RA patients with increased cIMT showed lower levels of CD36 compared with no increased cIMT $(67.09 \pm 27.50$ versus $170.43 \pm 38.80$, $P<0.001)$.

The PBMC membrane expression of CD36 MFI was significantly lower in patients with moderate and high disease activity $(n=22,64.31 \pm 16.72)$, when compared to patients with low disease activity $(n=11,129.78 \pm 13.73)$ or in remission $(n=34,158.2 \pm 13.66)(P<0.05)$.

3.2. Correlations Coefficients between cIMT, Clinical, and Laboratory Characteristics of $R A$ Patients. Correlation coefficients between cIMT and characteristics of RA patients are shown in Table 2. cIMT was negatively correlated with CD36 MFI and HDL-c and positively correlated with age, TC, Tg, AIP, anti-CCP, TNF $\alpha$, IL-6, CRP, and ox-LDL.

Figure 1 showed a negative correlation between CD36 MFI with TNF $\alpha(r=-0.729, P<0.001)$ and IL-6 $(r=$ $-0.822, P<0.001)$. In data not shown, we observed a negative correlation of CD36 MFI with ox-LDL $(r=-0.841$, $P<0.001)$. 

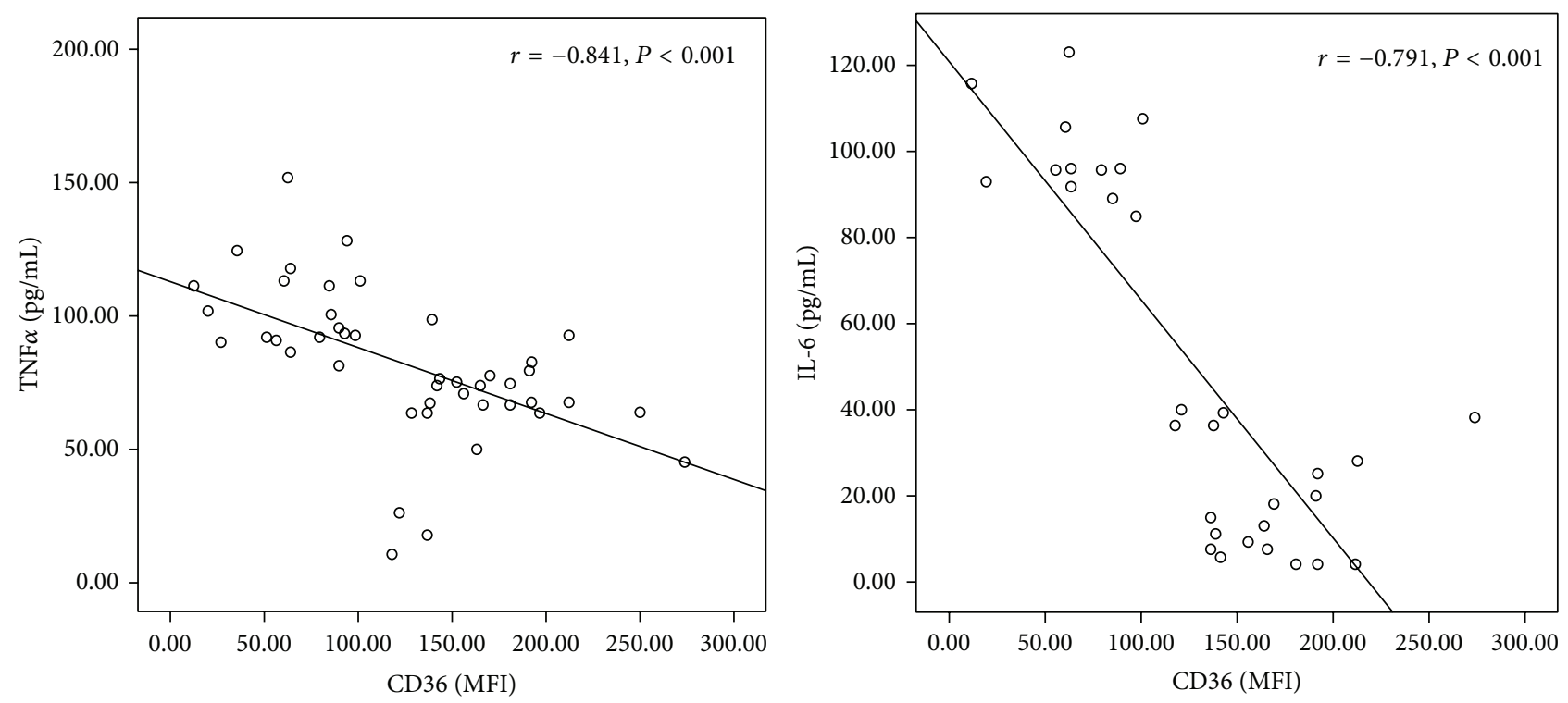

Figure 1: Correlation between serum TNF $\alpha$, IL-6, and CD36 MFI.

TABLE 2: Correlation coefficients between cIMT and characteristics of the groups evaluated.

\begin{tabular}{lcc}
\hline Baseline variable & \multicolumn{2}{c}{ cIMT $(\mathrm{mm})$} \\
\hline Age, years & 0.564 & $P$ \\
Disease duration, years & -0.063 & $<0.001$ \\
DAS28, units & 0.159 & 0.65 \\
TC, mg/dL & 0.331 & 0.26 \\
Tg, mg/dL & 0.393 & 0.03 \\
HDL-c, mg/dL & -0.316 & 0.009 \\
LDL-c, mg/dL & 0.285 & 0.04 \\
VLDL-c, mg/dL & 0.270 & 0.06 \\
ox-LDL, mg/dL & 0.457 & 0.07 \\
AIP, TC/HDL-c & 0.687 & 0.007 \\
ESR, mm/h & -0.180 & 0.01 \\
RF, IU/mL & -0.001 & 0.24 \\
CRP, mg/L & 0.579 & 0.99 \\
TNF $\alpha, \mathrm{pg} / \mathrm{mL}$ & 0.552 & 0.001 \\
IL-6, pg/mL & 0.681 & 0.002 \\
Anti-CCP, U/mL & 0.393 & $<0.001$ \\
CD36 & -0.578 & 0.05 \\
\hline
\end{tabular}

cIMT: carotid intima-media thickness; RA: rheumatoid arthritis; DAS28: disease activity score; TC: total cholesterol; Tg: triglycerides; HDL-c: high density lipoprotein cholesterol; LDL-c: low density lipoprotein cholesterol; VLDL-c: very low density lipoprotein cholesterol; AIP: atherogenic index of plasma; ESR: erythrocyte sedimentation rate; RF: rheumatoid factor; CRP: C-reactive protein; TNF $\alpha$ : tumor necrosis factor alpha; IL-6: interleukin 6; anti-CCP: anticyclic citrullinated peptide antibodies; MFI: mean fluorescence intensity. Spearman $r$ test.

\section{Discussion}

In this study, we showed that RA patients with subclinical atherosclerosis showed low membrane expression of CD36 in PBMC and increased serum proinflammatory cytokines (Table 1). The CD36 PBMC membrane expression was negatively correlated with cIMT, ox-LDL, TNF $\alpha$, and IL-6 (data not shown). We described a positive correlation between age, TC, Tg, ox-LDL, AIP, CRP, TNF $\alpha$, IL-6, and anti-CCP antibodies with cIMT (Table 2).

In endothelial cell cultures exposed to IL- 6 and $\mathrm{TNF} \alpha$, upregulation of the scavengers receptors- (SR-) A and oxLDL receptor- (LOX-) 1 was shown but not CD36 expression. Endothelial cells stimulated with human sera rich in IL-6 and $\mathrm{TNF} \alpha$ from RA patients; the CD36 expression increased and was not modified by IL- 6 or TNF $\alpha$ antagonists. This suggests that a different factor present in the serum of these patients, like ox-LDL, may be responsible for the upregulation of CD36 [17].

$\mathrm{TNF} \alpha$ promotes atherosclerosis through the inhibition of cholesterol efflux, favoring the cholesterol uptake by CD36 and other SR via protein kinase pathway. In THP-1 cells in the presence of ox-LDL, TNF $\alpha$ impaired the cholesterol efflux by downregulation of ATP-binding cassette (ABCA) proteins [18].

Boyer et al. showed the downregulation of membrane expression and mRNA levels of CD36 in culture of fresh PBMC from healthy donors in the presence of human recombinant TNF $\alpha$. In other experiment incubating PBMC with a humanized TNF $\alpha$ blocker (Adalimumab), the membrane and mRNA CD36 increased [19]. The authors concluded that different pathways were involved in the regulation of CD36. When TNF $\alpha$ was used, the signaling was mediated by a reduction in activated peroxisome proliferator-activated receptor gamma, whereas Adalimumab increased CD36 through redox signaling.

In our report, the membrane CD36 in PBMC was decreased in RA patients with higher cIMT; besides, a negative correlation between TNF $\alpha$ and membrane CD36 MFI was found. These support the findings observed in 
endothelial cells and PMBC cultures reported by Boyer et al. [19]. However, these results must be corroborated by further studies using similar approaches as described before.

In our patients, another possible explanation for the low levels of CD36 might be the proteolytical cleavage by ADAM17, which might result in more soluble CD36 [20]. It has been reported the protective role of the CD36 polymorphism, G573A, in plaque thickness in patients with early coronary artery disease [21].

In a more detailed analysis of our results, we looked for the influence of disease duration and treatment. We found that, RA patients with normal cIMT had longer disease duration and lower levels of TNF $\alpha$ and IL-6 (Table 1) probably due to the benefit of prolonged use of antirheumatic drugs in the prevention of subclinical atherosclerosis [22]. In vitro studies using methotrexate (MTX) favor the cholesterol efflux through activation of adenosine $\mathrm{A} 2$ receptor, which in turn prevents the foam cell differentiation and atherosclerosis plaque formation $[23,24]$. MTX might downregulate serum $\mathrm{TNF} \alpha$ in RA [25]. A large study that enrolled more than 8,000 patients using synthetic DMARDS compared with anti$\mathrm{TNF} \alpha$ users (11,000 approximately) showed a reduction in cardiovascular risk in both groups, even though the reduction was greater in the anti-TNF $\alpha$ treated patients [26, 27].

Based on our results, low PBMC CD36 membrane expression showed a negative correlation with cIMT, ox-LDL, TNF $\alpha$, IL-6, and DAS28. From the clinical standpoint, the interaction between these factors might reflect the importance of CD36 in the development of atherosclerosis in RA.

\section{Conclusion}

RA patients with subclinical atherosclerosis showed low membrane expression of CD36 in PBMC and increased serum proinflammatory cytokines. Translation of the results from these studies to the clinical field is difficult since the functional role of CD36 depends on the target cell. Further studies are needed to validate our findings and clarify the downregulation of CD36 in RA.

\section{Conflict of Interests}

The authors declare that they do not have conflict of interests.

\section{Acknowledgment}

The authors thank Professor Minoru Satoh, M.D. and Ph.D., for reviewing this paper.

\section{References}

[1] C. González-Juanatey, J. Llorca, and M. A. González-Gay, “Correlation between endothelial function and carotid atherosclerosis in rheumatoid arthritis patients with long-standing disease," Arthritis Research \& Therapy, vol. 13, no. 3, p. R101, 2011.

[2] L. L. Schott, A. H. Kao, A. Cunningham et al., "Do carotid artery diameters manifest early evidence of atherosclerosis in women with rheumatoid arthritis?" Journal of Women's Health, vol. 18, no. 1, pp. 21-29, 2009.
[3] I. Del Rincón, K. Williams, M. P. Stern, G. L. Freeman, D. H. O'Leary, and A. Escalantel, "Association between carotid atherosclerosis and markers of inflammation in rheumatoid arthritis patients and healthy subjects," Arthritis and Rheumatism, vol. 48, no. 7, pp. 1833-1840, 2003.

[4] J. Sokolove, M. J. Brennan, O. Sharpe et al., "Citrullination within the atherosclerotic plaque: a potential target for the anticitrullinated protein antibody response in rheumatoid arthritis," Arthritis and Rheumatism, vol. 65, no. 7, pp. 1719-1724, 2013.

[5] K. Ayada, K. Yokota, K. Kobayashi, Y. Shoenfeld, E. Matsuura, and K. Oguma, "Chronic infections and atherosclerosis," Clinical Reviews in Allergy \& Immunology, vol. 37, no. 1, pp. 44-48, 2009.

[6] K. J. Woollard, "Immunological aspects of atherosclerosis," Clinical Science, vol. 125, no. 5, pp. 221-235, 2013.

[7] R. L. Silverstein, "Inflammation, atherosclerosis, and arterial thrombosis: role of the scavenger receptor CD36," Cleveland Clinic Journal of Medicine, vol. 76, pp. S27-30, 2009.

[8] E. Bartoloni, Y. Shoenfeld, and R. Gerli, "Inflammatory and autoimmune mechanisms in the induction of atherosclerotic damage in systemic rheumatic diseases: two faces of the same coin," Arthritis Care and Research, vol. 63, no. 2, pp. 178-183, 2011.

[9] R. P. Choudhury, J. M. Lee, and D. R. Greaves, "Mechanisms of disease: macrophage-derived foam cells emerging as therapeutic targets in atherosclerosis," Nature Clinical Practice Cardiovascular Medicine, vol. 2, no. 6, pp. 309-315, 2005.

[10] M. E. C. Moreira and M. A. Barcinski, "Apoptotic cell and phagocyte interplay: recognition and consequences in different cell systems," Anais da Academia Brasileira de Ciencias, vol. 76, no. 1, pp. 93-115, 2004.

[11] R. L. Silverstein, W. Li, Y. M. Park, and S. O. Rahaman, "Mechanisms of cell signaling by the scavenger receptor CD36: implications in atherosclerosis and thrombosis," Transactions of the American Clinical and Climatological Association, vol. 121, pp. 206-220, 2010.

[12] S. Nozaki, H. Kashiwagi, S. Yamashita et al., "Reduced uptake of oxidized low density lipoproteins in monocyte-derived macrophages from CD36-deficient subjects," Journal of Clinical Investigation, vol. 96, no. 4, pp. 1859-1865, 1995.

[13] M. Janabi, S. Yamashita, K.-I. Hirano et al., "Oxidized LDLinduced NF- $\kappa \mathrm{B}$ activation and subsequent expression of proinflammatory genes are defective in monocyte-derived macrophages from CD36-deficient patients," Arteriosclerosis, Thrombosis, and Vascular Biology, vol. 20, no. 8, pp. 1953-1960, 2000.

[14] M. P. Young, M. Febbraio, and R. L. Silverstein, "CD36 modulates migration of mouse and human macrophages in response to oxidized LDL and may contribute to macrophage trapping in the arterial intima," Journal of Clinical Investigation, vol. 119, no. 1, pp. 136-145, 2009.

[15] F. C. Arnett, S. M. Edworthy, D. A. Bloch et al., "The American Rheumatism Association 1987 revised criteria for the classification of rheumatoid arthritis," Arthritis and Rheumatism, vol. 31, no. 3, pp. 315-324, 1988.

[16] P.-J. Touboul, M. G. Hennerici, S. Meairs et al., "Mannheim carotid intima-media thickness consensus (200-2006): an update on behalf of the advisory board of the 3rd and 4th Watching the Risk Symposium 13th and 15th European Stroke Conferences, Mannheim, Germany, 2004, and Brussels, Belgium, 2006," Cerebrovascular Diseases, vol. 23, no. 1, pp. 75-80, 2007. 
[17] M. Hashizume and M. Mihara, "Blockade of IL-6 and TNF- $\alpha$ inhibited oxLDL-induced production of MCP-1 via scavenger receptor induction," European Journal of Pharmacology, vol. 689, no. 1-3, pp. 249-254, 2012.

[18] A. Z. Sha Ma, Q. Zhang, and Z. Y. Song, "TNFa alter cholesterol metabolism in human macrophages via PKC- $\theta$-dependent pathway," BMC Biochemistry, vol. 14, no. 1, article 20, 2013.

[19] J. F. Boyer, P. Balard, H. Authier et al., "Tumor necrosis factor alpha and adalimumab differentially regulate CD36 expression in human monocytes," Arthritis Research and Therapy, vol. 9, no. 2, article R22, 2007.

[20] W. S. Driscoll, T. Vaisar, J. Tang, C. L. Wilson, and E. W. Raines, "Macrophage ADAM17 deficiency augments CD36-dependent apoptotic cell uptake and the linked anti-inflammatory phenotype," Circulation Research, vol. 113, no. 1, pp. 52-61, 2013.

[21] M. E. Rać, K. Safranow, M. Rać et al., "CD36 gene is associated with thickness of atheromatous plaque and ankle-brachial index in patients with early coronary artery disease," Kardiologia Polska, vol. 70, no. 9, pp. 918-923, 2012.

[22] S. L. Westlake, A. N. Colebatch, J. Baird et al., "The effect of methotrexate on cardiovascular disease in patients with rheumatoid arthritis: a systematic literature review," Rheumatology, vol. 49, no. 2, pp. 295-307, 2009.

[23] A. B. Reiss, S. E. Carsons, K. Anwar et al., "Atheroprotective effects of methotrexate on reverse cholesterol transport proteins and foam cell transformation in human THP-1 monocyte/macrophages," Arthritis and Rheumatism, vol. 58, no. 12, pp. 3675-3683, 2008.

[24] T. C. Bingham, E. A. Fisher, S. Parathath, A. B. Reiss, E. S. Chan, and B. N. Cronstein, "A2A adenosine receptor stimulation decreases foam cell formation by enhancing ABCA1-dependent cholesterol efflux," Journal of Leukocyte Biology, vol. 87, no. 4, pp. 683-690, 2010.

[25] P. Barrera, C. J. Haagsma, A. M. Boerbooms Th. et al., "Effect of methotrexate alone or in combination with sulphasalazine on the production and circulating concentrations of cytokines and their antagonists. Longitudinal evaluation in patients with rheumatoid arthritis," British Journal of Rheumatology, vol. 34, no. 8, pp. 747-755, 1995.

[26] D. H. Solomon, J. R. Curtis, K. G. Saag et al., "Cardiovascular risk in rheumatoid arthritis: comparing tnf- $\alpha$ blockade with nonbiologic DMARDs," American Journal of Medicine, vol. 126, no. 8, pp. 730-el7, 2013.

[27] X. Chen, K. Xun, L. Chen, and Y. Wang, “TNF- $\alpha$, a potent lipid metabolism regulator," Cell Biochemistry and Function, vol. 27, no. 7, pp. 407-416, 2009. 


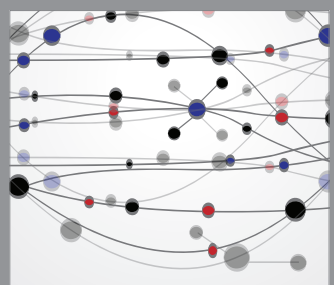

The Scientific World Journal
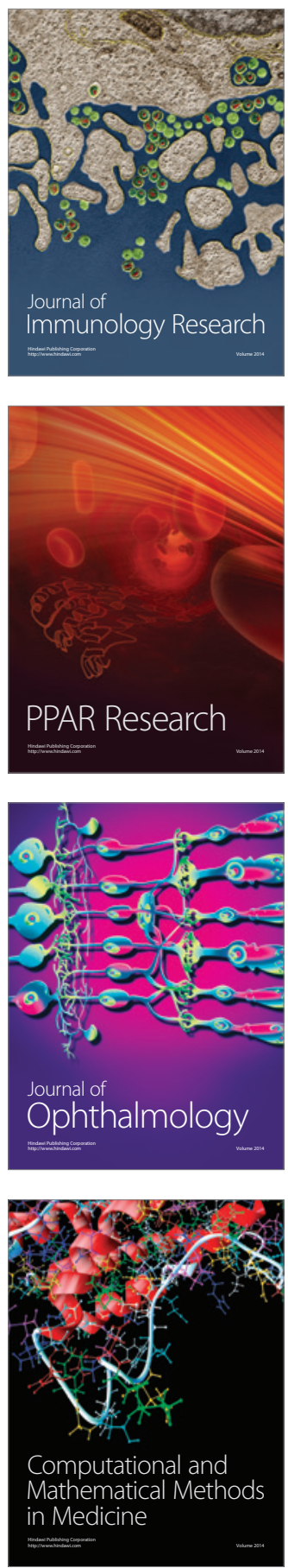

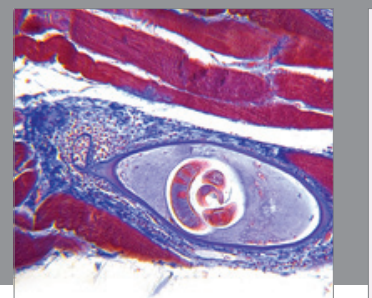

Gastroenterology

Research and Practice
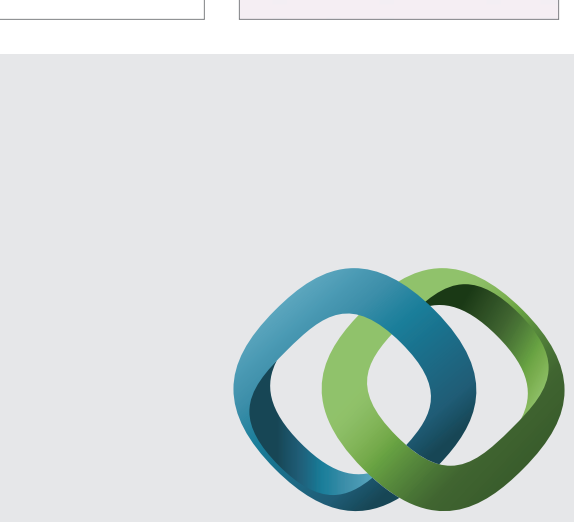

\section{Hindawi}

Submit your manuscripts at

http://www.hindawi.com
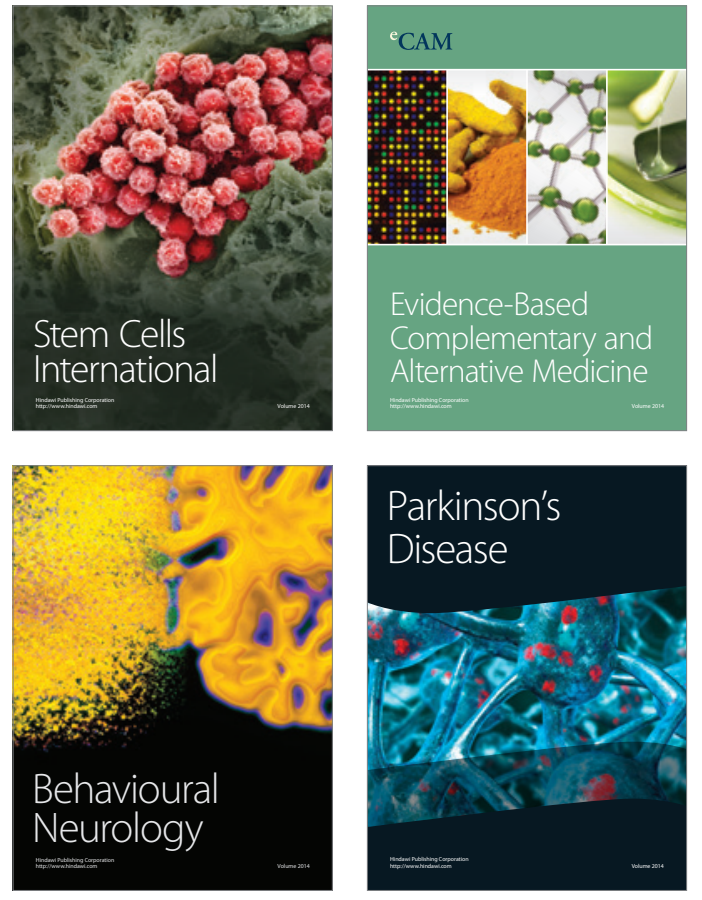
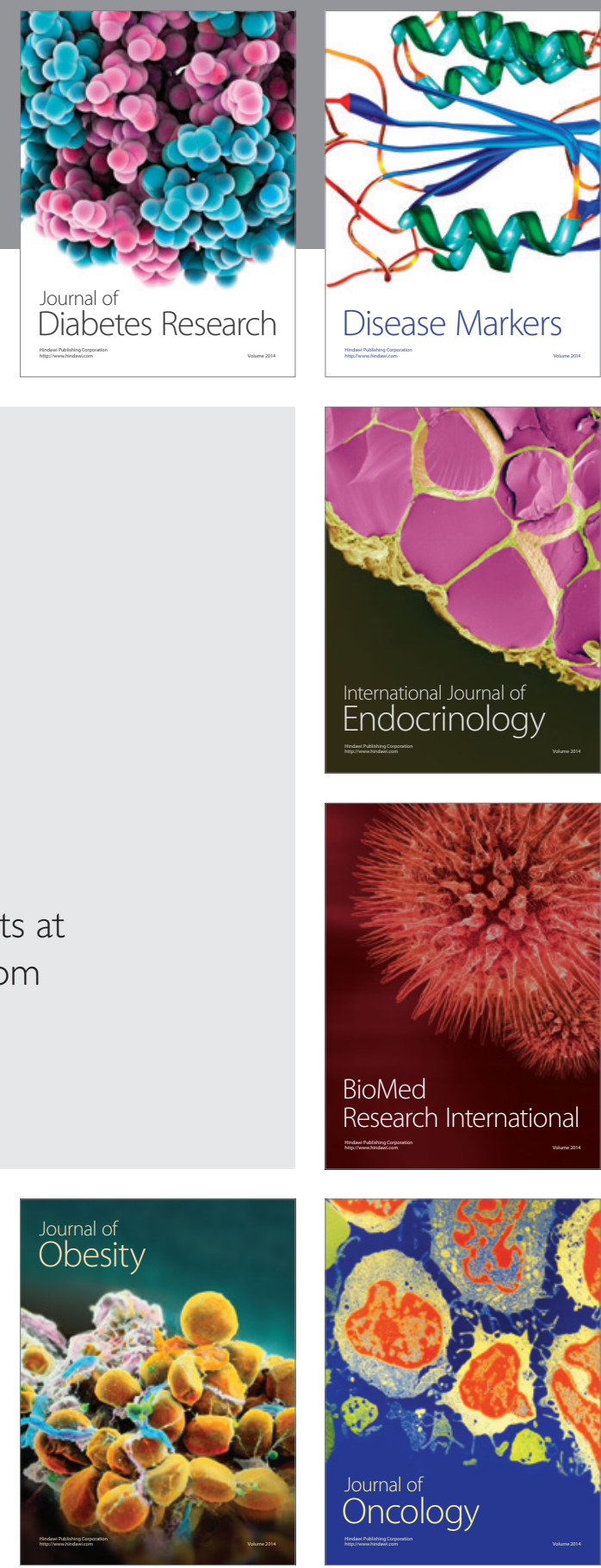

Disease Markers
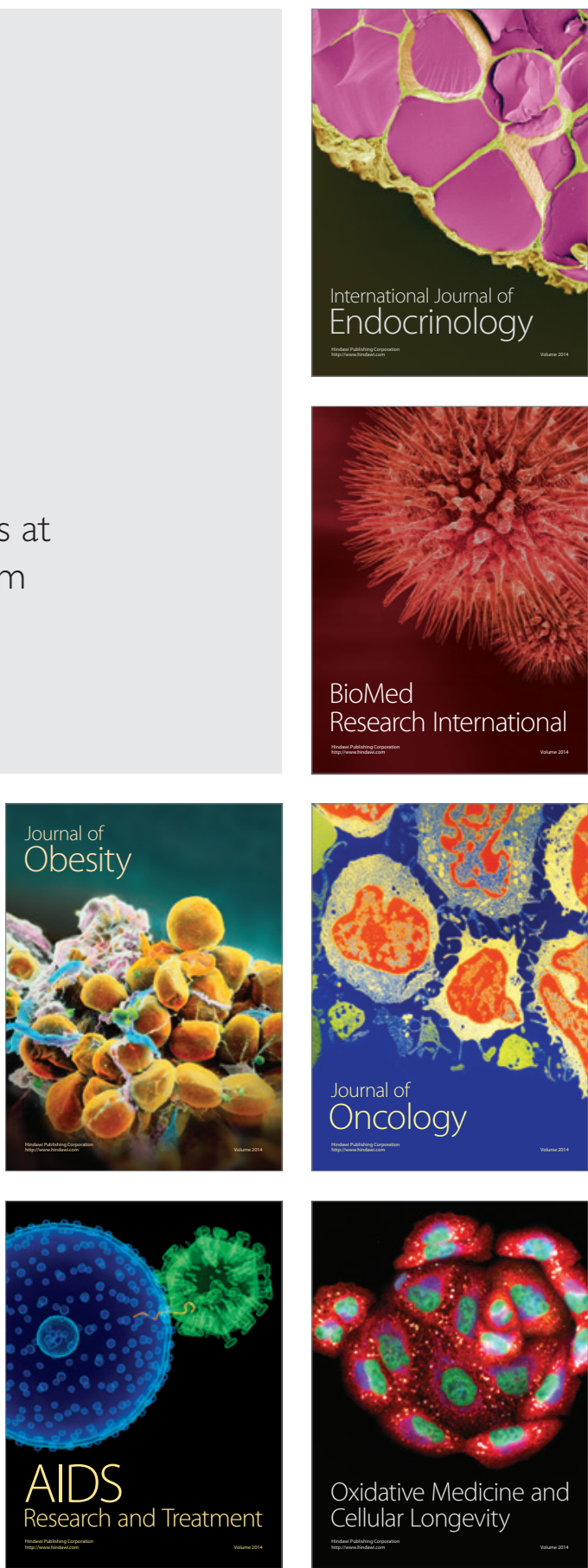